J. Dairy Sci. 93:2691-2694

doi:10.3168/jds.2009-3027

(C) American Dairy Science Association ${ }^{\circledR}, 2010$.

\title{
Technical note: A noninvasive urine collection device for female cattle: Modification of the urine cup collection method
}

\author{
G. J. Lascano, ${ }^{*}$ G. I. Zanton, ${ }^{*}$ A. J. Heinrichs, ${ }^{, 1}$ and W. P Weiss $†$ \\ *Department of Dairy and Animal Science, The Pennsylvania State University, University Park 16802 \\ †Department of Animal Sciences, The Ohio State University, Wooster 44691
}

\begin{abstract}
Total urine collection from female cattle requires the use of indwelling urinary catheters or an external device requiring secure attachment with adhesive to the animal; neither method is ideal for the welfare of the cattle. A urine collection device was developed to enable total urine collection in female dairy cattle without the use of adhesive to attach the device to the vulva of the animal; the device was a modification of one described previously for female cattle. The urine collection device was made from polypropylene with maximum dimensions (height $\times$ width $\times$ depth) of $17.5 \times 11.0 \times 6.0$ $\mathrm{cm}$ and an opening of approximately $42 \mathrm{~cm}^{2}$ to cover the vulva. The device was secured using a commercially available udder support harness that provided snapfasteners and support for the device to be positioned at the level of the vulva. At the point of attachment, a metal brace surrounded the device and was connected to the udder support by metal rings, which kept the urine cup in proper position as the animal arched to urinate. A metal O-clamp and pieces of rubber, serving as leak-proof washers, connected the bottom of the device to Gooch tubing. Another metal clamp was attached to a polyvinyl chloride adapter that was connected to a rubber hose, and urine was collected into carboys located on the floor approximately $1.5 \mathrm{~m}$ behind the animals. This modification of a urine cup allows several noninvasive total feces and urine collection studies of unrestricted length to be undertaken without the use of adhesive to attach the device. The floor-level collection system is a practical, portable, and handy system that will permit researchers to perform nutrient balance and metabolic studies on female cattle.
\end{abstract}

Key words: external urine collection system, noninvasive, dairy cattle

Separation and collection of urine and feces are necessary to evaluate nutrient balance in experiments with

Received December 22, 2009

Accepted February 13, 2010.

${ }^{1}$ Corresponding author: ajh@psu.edu
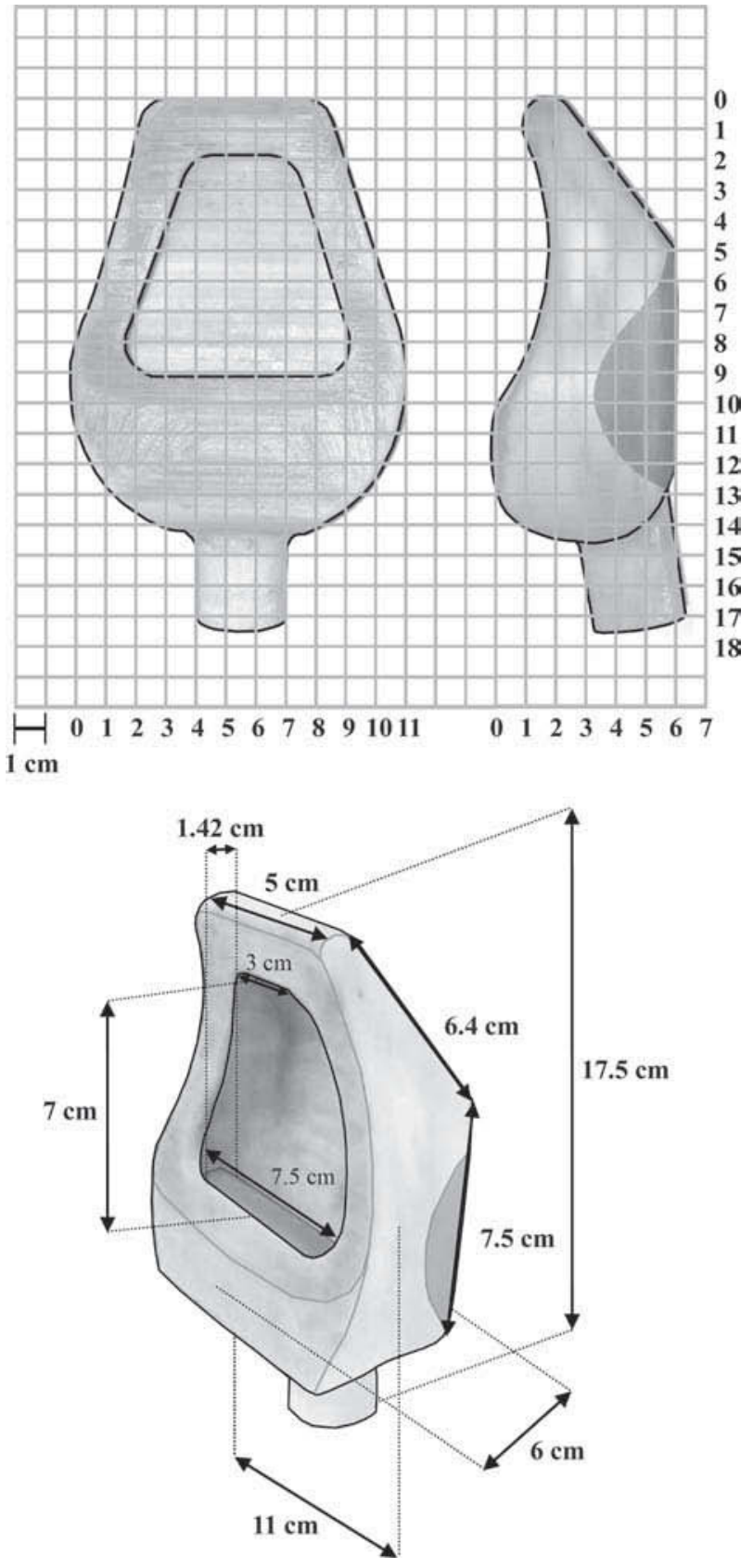

Figure 1. Urine cup device as modified from Fellner et al. (1988); the superimposed grid has squares representing 1-cm sides. 


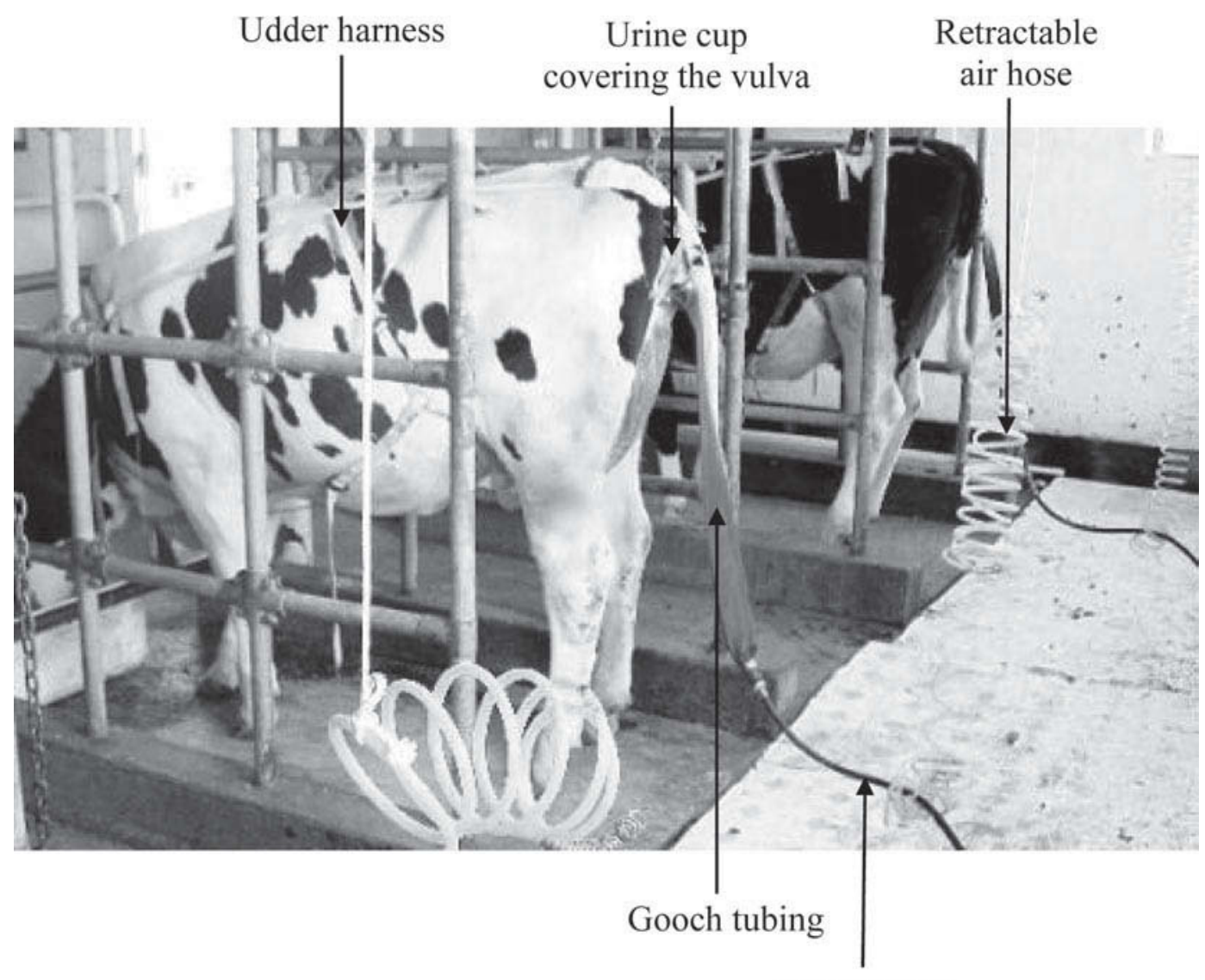

Rubber hose

Figure 2. Position of the urine cup and udder supports used to separate urine from feces in a total collection period with dairy heifers.

female cattle. Digestibility, metabolic, gas emission, and stable isotope studies could benefit from having a valid and safe technique to separate and completely collect fecal and urine output. Animal welfare concerns and risks of urinary tract infections have contributed to the reduced use of urinary catheters. In addition to urinary tract infections, other problems encountered when using urinary catheters include the expulsion of the catheters by cows during long-term collection and urine retention leading to an underestimation of urine output (Fellner et al., 1988); additionally, trained personnel are needed to install the urinary catheters. Fellner et al. (1988) developed a urine cup that avoided the problems of using catheters. Nevertheless, this device, and its subsequent modifications (Cao et al., 2009), retained animal welfare concerns because it was glued to the animal with different types of adhesives that had to be strong, with the potential of injuring the skin of the animal. Another limitation of the former model was that the urine container had to be lower than the animal (either placed underground or at ground level with an elevated animal), and many research facilities do not have the potential for these special modifications, restricting its use. Thus, we describe a modification of the device of Fellner et al. (1988) to provide a floor-level collection technique without the use of an adhesive for attachment to conduct total collection and separation of urine and feces.

The urine cup devices were fabricated from polypropylene and joined by heat fusion (Figure 1) by the Penn State Engineering Services using a model (Weiss and Wyatt, 2000) of a urine cup based on the design of Fellner et al. (1988). The device was held in place over the vulva using an udder support harness $(\mathrm{C} 17682 \mathrm{~N}$, Nasco, Fort Atkinson, WI; Figure 2). A metal brace surrounded the urine cup and was connected to the udder support by metal rings, which allowed the urine cup to be positioned directly over the vulva without the use of an adhesive (Figure 3A). Gooch tubing (50 mm outside diameter, $1 \mathrm{~m}$ long) provided an approximately 2-L reservoir for the accumulation of urine; the accumulated urine served as a source of pressure to force the urine through a polyvinyl chloride coupling into a rubber hose (9.5 mm inside diameter; Figure 3B) to the collecting carboy approximately $1.5 \mathrm{~m}$ behind the animal (Figure 2). The inside diameter of the rubber hose 
A.

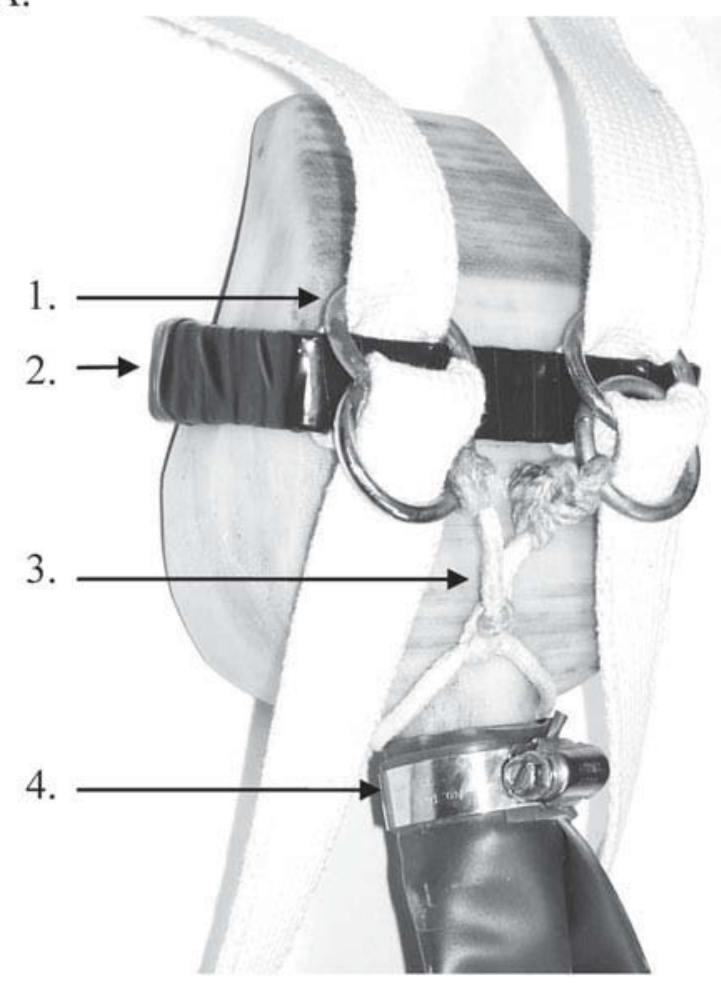

C.

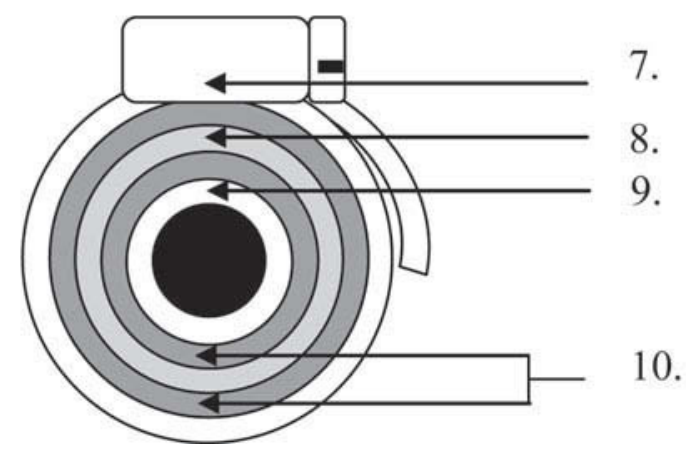

B.

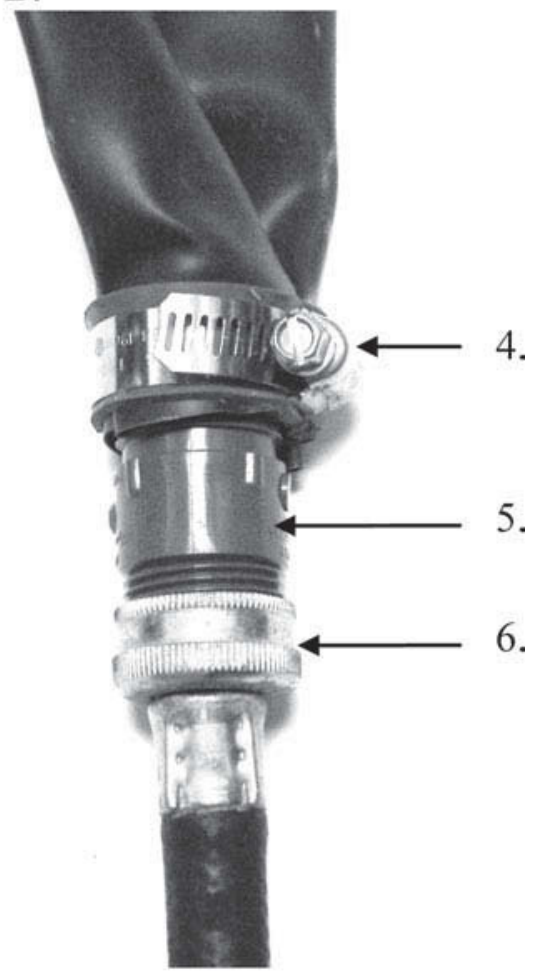

Figure 3. Detailed structure of the modified urine cup collection device. A) Apparatus to position and attach the urine cup to the udder support; B) connection of the Gooch tubing to the hose for transmitting urine from the animal to the carboy; C) cross-sectional view of the connection between the urine cup to the Gooch tubing and the Gooch tubing to the threaded coupling (not drawn to scale). $1=$ rings $[25.4$ mm inside diameter (i.d.)] with udder support straps interwoven to maintain the vertical position of the brace and urine cup; $2=$ metal brace (3.175 mm thickness; 3 sides of a rectangle $11.43 \mathrm{~cm}$ long $\times 5 \mathrm{~cm}$ wide) to position urine cup against the animal; not attached to the urine collection device; $3=$ rope ( $4.76 \mathrm{~mm}$ thickness) attaching urine cup to the rings to maintain the vertical position of the urine cup; $4=$ clamp attachments joining Gooch tubing to adjoining pieces, depicted in detail in panel C; $5=$ threaded polyvinyl chloride $(\mathrm{PVC})$ coupling $(25.4 \times 19.05 \mathrm{~mm})$ connecting Gooch tubing to hose; $6=$ hose (9.525 mm i.d.); $7=$ O-clamp (adjustable from 38.10 to $44.45 \mathrm{~mm}$ ); $8=$ Gooch tubing (7.62 $\mathrm{cm}$ i.d. and $1 \mathrm{~m} \mathrm{long}) ; 9=$ urine cup or PVC coupling; and $10=$ rubber piece $(1.59 \mathrm{~mm}$ thick $\times 19.05 \mathrm{~mm}$ wide $\times 10.80 \mathrm{~cm}$ circumference).

can be increased for animals excreting greater quantities of urine without any other modifications as long as the lowest point of the Gooch tubing is higher than the highest point of the collection carboy. A retractable air hose was used to hold the rubber hose for urine flowing from the Gooch tubing to the carboy behind the animal (Figure 2). The 3 pieces transferring urine from the animal to the carboy were made leak-proof using an
O-clamp (adjustable from 38.10 to $44.45 \mathrm{~mm}$ ) and 2 rubber washers fastening the bottom of the urine cup to a Gooch tube and attaching the Gooch tubing to the plastic coupling attached to a rubber hose (Figure $3 \mathrm{C})$.

The modification of the urine cup model allowed several noninvasive total feces and urine collection studies to be undertaken (Lascano et al., 2009; Zanton and 
Heinrichs, 2009). By positioning the urine cup over the vulva with the udder support system, the modification allowed the animal to arch her back while urinating, with the urine flowing directly into the cup without the need of an adhesive applied to the skin of the animal. The udder support and the use of a retractable air hose allowed the animal to have free movement and did not interfere with her normal activity while housed in the stalls (Figure 2). This configuration also minimized the possibility of the animal getting tangled in the urine flow lines and displacing the urine cup from its optimal placement. The urine output and creatinine concentration data of Zanton and Heinrichs (2009), obtained using the urine collection system described herein, indicated a direct relationship between creatinine concentration, BW, and urine output, which the authors suggested could be used to predict urine output without reliance on total collection. The closeness of the data obtained in that experiment and other experiments based on total collection of urine give confidence in the validity of the collection method used in that experiment and detailed here. Unlike the recent (Cao et al., 2009) modification of the urine cup of Fellner et al. (1988), which required an adhesive or the use of urinary catheter, the procedure described here can be used for extended collection periods, and has been used in experiments in our laboratory for up to $8 \mathrm{~d}$ of total collection without any complications. This modification also allows the urine to flow to a carboy located on the floor at a distance from the animal, thereby eliminating the need for special facilities to collect urine.

\section{REFERENCES}

Cao, Z. J., M. Ma, X. Y. Yan, S. L. Li, and X. M. Zhang. 2009. A simple urine-collecting apparatus and method for cows and heifers. J. Dairy Sci. 92:5224-5228.

Fellner, V., M. F. Weiss, A. T. Belo, R. L. Belyea, F. A. Martz, and A. H. Orma. 1988. Urine cup for collection of urine from cows. J. Dairy Sci. 71:2250-2255.

Lascano, G. J., G. I. Zanton, F. X. Suarez-Mena, and A. J. Heinrichs. 2009. Effect of limit feeding high- and low-concentrate diets with Saccharomyces cerevisiae on digestibility and on dairy heifer growth and first-lactation performance. J. Dairy Sci. 92:5100-5110.

Weiss, W. P., and D. J. Wyatt. 2000. Effect of oil content and kernel processing of corn silage on digestibility and milk production by dairy cows. J. Dairy Sci. 83:351-358.

Zanton, G. I., and A. J. Heinrichs. 2009. Digestion and nitrogen utilization in dairy heifers limit-fed a low or high forage ration at four levels of nitrogen intake. J. Dairy Sci. 92:2078-2094. 